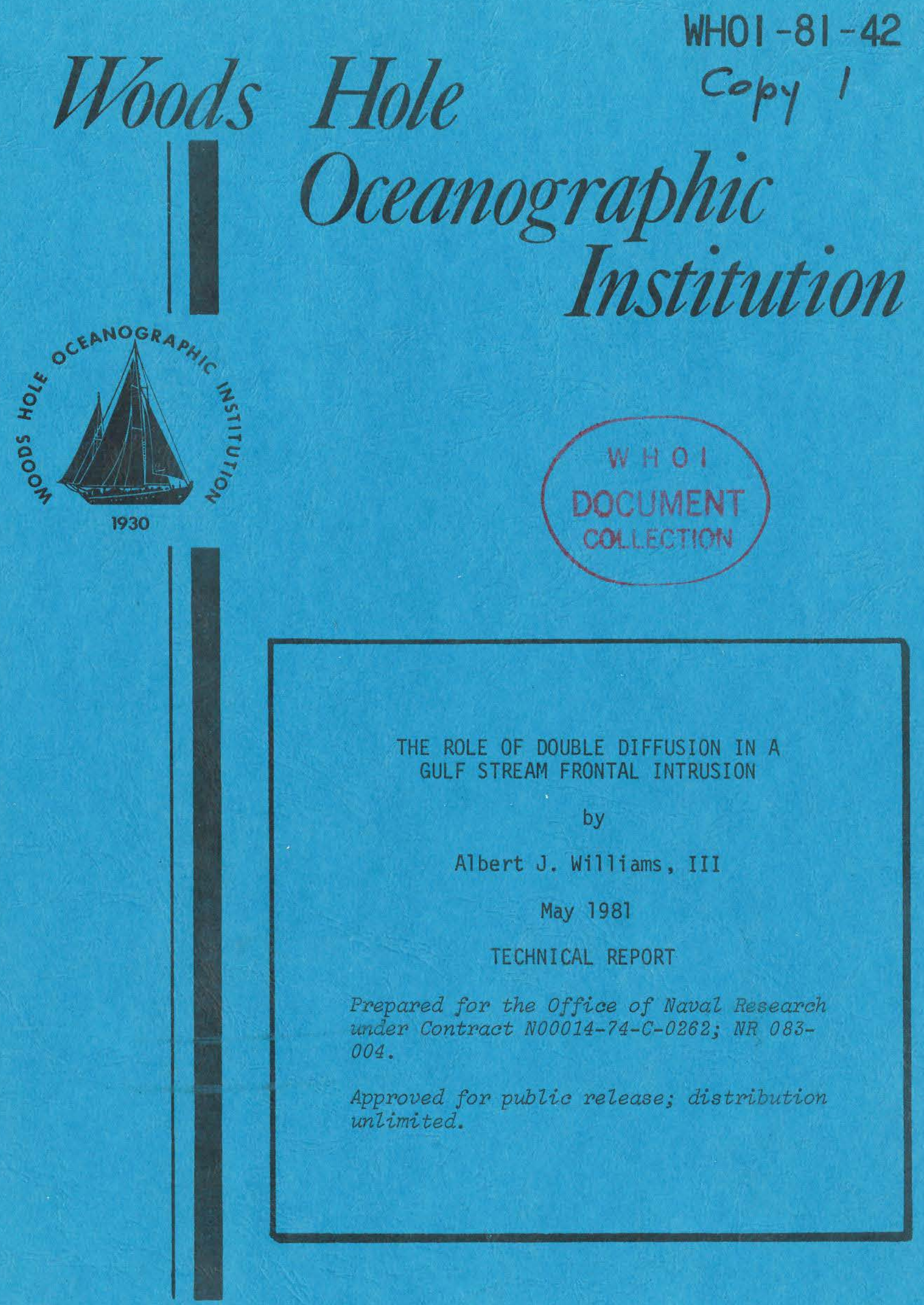

IVOODS HOLE, MASSACHUSET TS 02543 
WHOI $-81-42$

THE ROLE OF DOUBLE DIFFUSION IN A GULF STREAM FRONTAL. INTRUSION

by

\author{
Albert J. Williams, III \\ WOODS HOLE OCEANOGRAPHIC INSTITUTION \\ Woods Hole, Massachusetts 02543
}

May 1981

TECHNICAL REPORT

Prepared for the Office of Naval Research under Contract N00014-74-C-0262; NR 083-004.

Reproduction in whole or in part is permitted for any purpose of the United States Govermment. In citing this report in a bibliography, the reference given should be to: Joumal of Geophysical Research 86(C3): 1917-1928 (March 20, 1981).

Approved for public release; distribution unlimited.

Approved for Distribution: Earl E. Hays, Chairman Department of Ocean Engineering 


\title{
The Role of Double Diffusion in a Gulf Stream Frontal Intrusion
}

\author{
AlberT J. Williams, III \\ Woods Hole Oceanographic Institution, Woods Hole, Massachusetts 02543
}

\begin{abstract}
Double diffusive convection is possible where large vertical gradients in temperature and salinity tend to compensate in density. Frontal intrusions have these large gradients and can provide the possibility for a salt finger interface at one boundary and a diffusive interface at the other. But large vertical gradients of velocity are present at the boundaries of intrusions, which cause mechanical stirring and turbulent mixing as well. In the exceptionally active intrusions at the Gulf Stream Front near $38^{\circ} \mathrm{N} 69^{\circ} \mathrm{W}$, a convective process resulting from incomplete mechanical mixing was observed photographically on both intrusive boundaries.
\end{abstract}

\section{INTRODUCTION}

\section{Mixing}

Mixing of dissimilar fluid in the ocean occurs by stirring of one fluid into the other at finer and finer scales until molecular diffusion erases the differences in temperature and salinity of the components [Eckart, 1948]. This process can occur in the absence of mechanical energy where the temperature and salinity differences tend to compensate in density. The energy source for this mixing is the gravitational potential of an unstable distribution of the density field owing to salt in one case and to temperature in the other case. Vertical mixing can occur in these cases through the processes of double diffusion [Turner, 1967, 1968]. Since density anomalies owing to temperature differences diffuse 2 orders of magnitude faster than density anomalies owing to salinity, a mechanism exists by which the density contribution from temperature can be separated from the density contribution of salt. Where cool fresh water overlies warm salty water, a thin diffusive interface forms that generates cool salty water on its lower side and warm fresh water on its upper side. Convection removes these fluids and keeps the interface sharp. Where warm salty water overlies cool fresh water, a thick interface of vertical, closepacked, counterflowing cells called salt fingers forms. The individual cells exchange heat with their counterflowing neighbors, but the net effect of this heat exchanger is to transport salt and heat downward. The cells become unstable at the edges of the interface, forming puddles of cool salty water at the lower edge and warm fresh water at the upper edge. Again, convection removes these fluids from the interface region.

In the quiet ocean a thick region of compensating temperature and salinity gradient develops a thermohaline staircase in which double diffusion at high gradient regions called interfaces alternates with convective stirring in low gradient regions called layers [Stern and Turner, 1969]. The interfaces are thin, steady, low Reynolds number flows, while the layers are thick flows with unsteady convection and turbulence. The flow changes from laminar to turbulent at the edges of the interface. Thermohaline staircases with layers $10-100 \mathrm{~m}$ thick have been observed in the ocean in regions far from fronts and supposedly not subject to large velocity shears [Tait and Howe, 1968; Molcard and Williams, 1975].

The other source of vertical mixing is mechanical stirring [Munk and Garrett, 1973]. Vertical shear in horizontal velocity has a rotational component about a horizontal axis that pro-

Copyright (c) 1981 by the American Geophysical Union. duces overturning if the gravitational restoring torque is not sufficient. Where the gradient Richardson number

$$
R_{i}=\frac{q}{\rho} \frac{(\Delta \rho / \Delta z)}{(\Delta u / \Delta z)^{2}}
$$

where $\rho$ is density, $g$ is gravitational acceleration, $u$ is horizontal velocity, and $\Delta / \Delta z$ is the vertical gradient over an interval $\Delta z$, drops and remains below $\frac{1}{4}$, a Kelvin-Helmholtz instability can grow causing the fluid to overturn in rolls [Woods and Wiley, 1972; Osborn, 1974]. While this certainly puts an upper bound on the mean shear, fluctuations in shear owing to internal waves may cause transient instabilities to occur at lower mean shear. In addition, internal wave fields may produce local particle velocities exceeding the wave phase velocity to jet fluid from one layer into another, although this is estimated to be less important than shear instability. Secondary instabilities on these rolls or jets convert the large-scale structures into finger-scale turbulence ending in mixing and dissipation of the kinetic energy. In the upper thermocline, such mixing events are common.

The measurement and interpretation of Richardson number is difficult. Since the condition necessary for an overturning event is a finite amplitude perturbation in addition to a low Richardson number and sufficient time for the instability to grow, transient measurements made by a sinking instrument may suggest overturning conditions, but cannot prove them. In this paper, I have distinguished the low Richardson number cases from the higher Richardson number cases to facilitate interpretation of the microstructure observations. The interpretations may well be incorrect in some cases because of the limitations on our knowledge of the true appropriate conditions affecting overturning.

\section{Frontal Intrusions}

Ocean mixing does not occur simply by vertical mixing except perhaps in special situations. In general, the mixing process occurs by horizontal advection of fluid over great distances and vertical mixing over small distances. The Gulf Stream is such an advective feature. The boundary between Gulf Stream water and slope water is a sloping frontal surface across which properties change abruptly. Such fronts are common even far from major current systems, presumably reflecting the large-scale stirring processes tending to mix the ocean [Voorhis et al., 1976; Horne, 1978]. Horizontal advection at this scale is parallel to the frontal surface. However, intrusions across the mean frontal surface greatly increase the surface area for vertical mixing. Intrusions are typically tens of meters 
thick and penetrate several kilometers across the front. It is here that significant mixing occurs. The intrusions represent the intermediate scale of stirring and are responsible for the dominant fine structure features near fronts.

Intrusions by necessity are intermediate in density between the water above them and that beneath. If one considers only intrusions that produce an inversion in temperature or salinity or both (these are the most recognizable intrusions at any rate), then the upper or lower interface will have the correct temperature and salinity gradients for double diffusion to occur. Thus many, if not most, oceanic intrusions provide the conditions for double diffusion [Turner, 1978]. The intrusion also has velocity shear at the interfaces, partly from advective velocities and partly from internal wave motion. Either may be responsible for mixing, so the question arises, What are the vertical mixing processes in intrusions? It is the purpose of this paper to answer this question for the Gulf Stream frontal intrusions studied.

\section{Coupled Momentum, Heat, and Salt Diffusion}

A discontinuous interface between two well-mixed water masses differing in temperature and salinity diffuses in time to a thicker, continuous gradient region with a distribution in properties

$$
\begin{gathered}
T(x, t)=\frac{T_{1}+T_{2}}{2}+\frac{T_{2}-T_{1}}{2} \operatorname{erf}\left(W_{T}\right) \\
S(x, t)=\frac{S_{1}+S_{2}}{2}+\frac{S_{2}-S_{1}}{2} \operatorname{erf}\left(W_{S}\right) \\
\operatorname{erf}(W)=\frac{2}{\sqrt{\pi}} \int_{0}^{W} e^{-u^{2}} d u \\
W_{T}=\frac{x}{2}\left|\frac{c}{k t}\right|^{1 / 2} \\
W_{S}=\frac{x}{2} \frac{1}{\sqrt{K}_{S} t}
\end{gathered}
$$

where $\kappa=1.4 .10^{-3} \mathrm{cal} \mathrm{s}^{-1} \mathrm{~cm}^{-1}{ }^{\circ} \mathrm{C}^{-1}$ is the thermal conductivity of water, $c=1.0 \mathrm{cal} \mathrm{cm}^{-1}{ }^{\circ} \mathrm{C}^{-1}$ is the heat capacity, $K_{S}=1.48 .10^{-5} \mathrm{~cm}^{2} \mathrm{~s}^{-1}$ is the diffusivity of salinity, and $x$ and $t$ are the distance from the interface and the elapsed time, respectively [Williams, 1975]. This distribtuion assumes no motion of the fluid, a requirement that will not be met if the diffusion of heat and salt affects density, as it will, unless the interface is horizontal; even then the problem quickly becomes a Rayleigh convection problem. However, for a short time this problem can be neglected if the density effect is small. The heat diffuses more rapidly than salt and produces a density distribution

$$
\rho(x, t)=\alpha T(x, t)+\beta S(x, t)+\rho(0, t)
$$

where $\alpha \sim 2.10^{-4} \mathrm{gm} \mathrm{cm}^{-3}{ }^{\circ} \mathrm{C}^{-1}$ and $\beta=7.8 .10^{-4} \mathrm{gm} \mathrm{cm}^{3} \% 0^{-1}$, that can have its maximum and minimum value on either side of the interface and close to it.

The two situations that approximate this initially discontinuous interface in nature are the diffusive interface and the salt finger. In the diffusive interface the low density fluid that develops above the interface is removed by Rayleigh convection and replaced by new fluid from the interior of the layer. This returns the system to the nearly discontinuous interface of the start.
A salt finger is similarly renewed by water entering one end of the convection cell from the interior of one layer and being dumped out the other end when the heat, but not much of the salt, has diffused into the adjacent cell. The true interface in the salt finger is the vertical interface between fingers. More or less continuous flow through the fingers keeps the salinity distribution at this interface nearly discontinuous.

One can imagine a discontinuous interface between two well-mixed water masses differing in temperature, salinity, and velocity. Viscosity will cause the velocity distribution to develop as

$$
\begin{gathered}
V(x, t)=\frac{V_{1}+V_{2}}{2}+\frac{V_{2}-V_{1}}{2} \operatorname{erf}\left(W_{\nu}\right) \\
W_{\nu}=\frac{x}{2}\left(\frac{1}{\nu t}\right)^{1 / 2}
\end{gathered}
$$

where $\nu=10^{-2} \mathrm{~cm}^{2} \mathrm{~s}^{-1}$ is the kinematic viscosity of water. The velocity diffuses more rapidly than does heat so that the problem reverts to the double diffusion of heat and salt near the interface after a short interval.

In a Kelvin-Helmholtz instability a density interface becomes distorted by a roll about an axis through the interface. The interface itself is stretched as it is made wavy, than S shaped, then double-spiral shaped. The local elongation of the interface brings fluid toward the interface and increases the gradients of salinity, temperature, and velocity. At the same time the separation between wraps of the spiral decrease, and when second-order instabilities occur, the distance between adjacent interfaces decreases more. At a certain stage the running down of the velocity gradient across each interface, owing to viscosity and the thinning of the filaments between interfaces, erases the shear motion while the temperature and salinity gradients remain.

Heat diffusion next produces a density contrast outlining each interface with light fluid on one side and with heavy fluid on the other. The interfaces are spread through a thick volume, the thickness being the diameter of the overturning roll. The buoyant fluid throughout this volume then rises, and the dense fluid sinks, not just to the region bordering the overturned patch, but through that region as well if the density differences are sufficiently great.

The event described above is intermittent. Were mechanical energy continuously available to stir the overturned region, the buoyant fluid would not separate from the dense fluid but would be kept in close proximity to it until the salinity differences disappeared. But when the shear instability occurs intermittently, the conditions resemble the model of an initially discontinuous velocity distribution that subsequently runs down. Since the generation of buoyancy from double diffusion processes is extended to a thick region by the rapidly diffused velocity gradients of an overturning event, this mixing is a sort of triple diffusion process.

\section{INSTRUMENTATION}

Identification of mixing processes in the ocean requires sensors which can distinguish mechanical stirring from diffusive mixing. The vertical profile of temperature and salinity provides information about vertical gradients and permits layers and interfaces to be identified; but these are the raw materials and the products of mixing, and not the mixing structures themselves. The mixing structures are smaller than the spatial resolution of ordinary temperature and salinity sensors, and 
they are distributed in space in characteristic arrangements that are difficult to guess from a vertical profile.

For the present study an optical imaging system resolved the microstructure [Williams, 1975]. This system produces shadowgraphs of index of refraction inhomogeneities in a horizontal viewing path $2 \mathrm{~cm}$ in diameter and $80 \mathrm{~cm}$ long. Shadowgraph images show the edges of structures as shadows, correctly represented in size, shape, and position [Williams, 1975]. Variations in index of refraction gradient that occur at the edges of structures from the mismatch in distribution of temperature gradient and salinity gradient focus collimated light to produce a bright outline of one side of an interface and defocus the light to cast a shadow of the other side of an interface. The effect is to outline the projection of each interface along the viewing direction with a light and dark line on the shadowgraph.

From the discussion of mixing processes previously, the expected shadowgraph and vertical temperature and salinity profile signatures of each mixing process can be summarized:

1. Salt fingers will display regular vertical bands at an interface where a mixed layer of warm salty water overlies a mixed layer of cooler less salty water. At the edges of the fingering interface there will be irregular vertical structures owing to buoyant plumes from the interface which penetrate the mixed layers. Examples of salt finger images are 2509 and 4310 in Figure 5.

2. Diffusive interfaces will display irregular vertical structures from buoyant plumes on either side of a sharp interface that separates a mixed layer of cool fresh water from a warm salty layer beneath. The interface itself will only appear in the shadowgraph image as a horizontal band if the entire optic axis coincides with the interface. There are no examples observed of this type.

3. Mechanically stirred regions will display chaotic structure in a thick region that will have little overall vertical gradient in temperature and salinity. While the mixing event is young, there will be little preference for vertical alignment of the structures. Image 4039 is an example of this, but contains some fine vertical structure as well.

4. 'Triple diffusion' or older mechanically stirred regions will display irregular vertical structure through a mixed or partly mixed region and even into the regions on either side. The clearest example of penetration is image 2238, while an example of mixed and convecting flow is 3197 .

The instrument used in this work is a freely sinking vehicle containing the optical imaging system described above, a conductivity-temperature-pressure recorder, and a velocity shearmeter [Williams, 1974a]. This instrument, Scimp (self contained imaging microprofiler), sinks at $12 \mathrm{~cm} / \mathrm{s}$, its buoyancy adjusted by acoustic commands from the surface vessel which cause it to jettison heavy or light fluid as required. The optical viewing volume is undisturbed by any mechanical structure beneath it. Even in a velocity shear zone the flow upward through the volume is not more than $30^{\circ}$ from vertical, so it is reasonable to dismiss the possibility that the vehicle generates the microstructure it observes. Flutter in the attitude of the vehicle is not apparent nor is it expected with the low drag forces, large mass, and distributed drag areas. When crossing a shear zone, the instrument rolls, but the roll is apparently heavily damped because there is no sharp peak in the spectrum of the velocity shear sensor as would occur if the vehicle had a characteristic roll or flutter motion.

The velocity shear sensor is an acoustic pulse travel time current meter with two horizontal axes, suspended $50 \mathrm{~cm}$ be- neath the center of drag of Scimp [Williams and Tochko, 1977; Gytre, 1975]. To a first approximation the signal recorded from the shearmeter is the velocity difference over $50 \mathrm{~cm}$. The exact response is more complicated because the sensor signal is actually a band pass filtered representation of the velocity profile with phase lag (P. M. Hendricks and G. Rodenbush, unpublished manuscript, 1977). The reconstruction of the true velocity profile in the wave number range $10^{-2} / \mathrm{m}$ to $10 / \mathrm{m}$ should be possible eventually by the process of forming the complex Fourier transform of the velocity series, multiplying it by the response function of the vehicle, and retransforming to obtain a corrected velocity profile. The second part of this process has not been done successfully yet, so the velocity shear at the center of its passband, $50 \mathrm{~cm}$, will be used in this interpretation.

The profile described in this paper produced two recordings: a tape (each record of which contained 16 bit measurements of temperature, conductivity, and pressure, an 8 bit measurement of azimuth, and two 12 bit measurements of velocity digitized every $200 \mathrm{~ms}$ ) and an $8 \mathrm{~mm}$ movie of shadowgraph images exposed once a second. The tape data were plotted as temperature, density, pressure, and two axes of velocity against tape record number. On each frame of the movie the record number is displayed so the images can be correlated to the plot. The movie and the plot are the principal evidence for the analysis to follow.

I have estimated the Richardson number to determine the stability of interfaces by using the plotted density and velocity. The current meter output is filtered before digitizing at 0.2 $\mathrm{Hz}$ which at $12 \mathrm{~cm} / \mathrm{s}$ sink rate becomes $60 \mathrm{~cm}$ wavelength, and the response of the vehicle to shear attenuates its response to velocity variations exceeding $50 \mathrm{~cm}$ in vertical extent, so the instrument approximately reads the velocity difference between the sensor and the center of drag or the shear over 50 $\mathrm{cm}$. Many density steps are sharper than this, and the shear may be sharper as well; but since the shear cannot be resolved to better than $50 \mathrm{~cm}$, the density step has been assumed to occur over $50 \mathrm{~cm}$ too for calculating the Richardson number. If the actual density step and shear occur over $25 \mathrm{~cm}$, the Richardson number should be $\frac{1}{4}$ as large as calculated. Thus the errors in the method of calculating Richardson number overestimate in the direction of stability.

\section{Gulf STREAM FronT}

In November 1975, as part of a study of the fine structure and microstructure of the Sargasso sea, a series of stations were made in the Gulf Stream. Simultaneous drops of several instruments in the highly variable layered structure of this region provided intercomparisons between the microstructure recorder (MSR) [Gregg, 1975] and Scimp and between the Camel [Osborn, 1974, 1978] and Scimp.

The MSR measures temperature microstructure with a fast thermistor and is capable of estimating the rate of thermal dissipation through the temperature variance. For a portion of Scimp dive 18, MSR recorded a temperature profile that agreed with that recorded by Scimp down to $50 \mathrm{~cm}$ thick features, confirming the calculation from launch times and sink rates that both instruments sampled that portion of the water column within several minutes of one another and probably within $10 \mathrm{~m}$ horizontally. Figure 1 is a qualitative comparison of the measurements of microstructure by these two instruments. The temperature profile is the common parameter between the two measurements.

The upper curve is the temperature variance measured by 

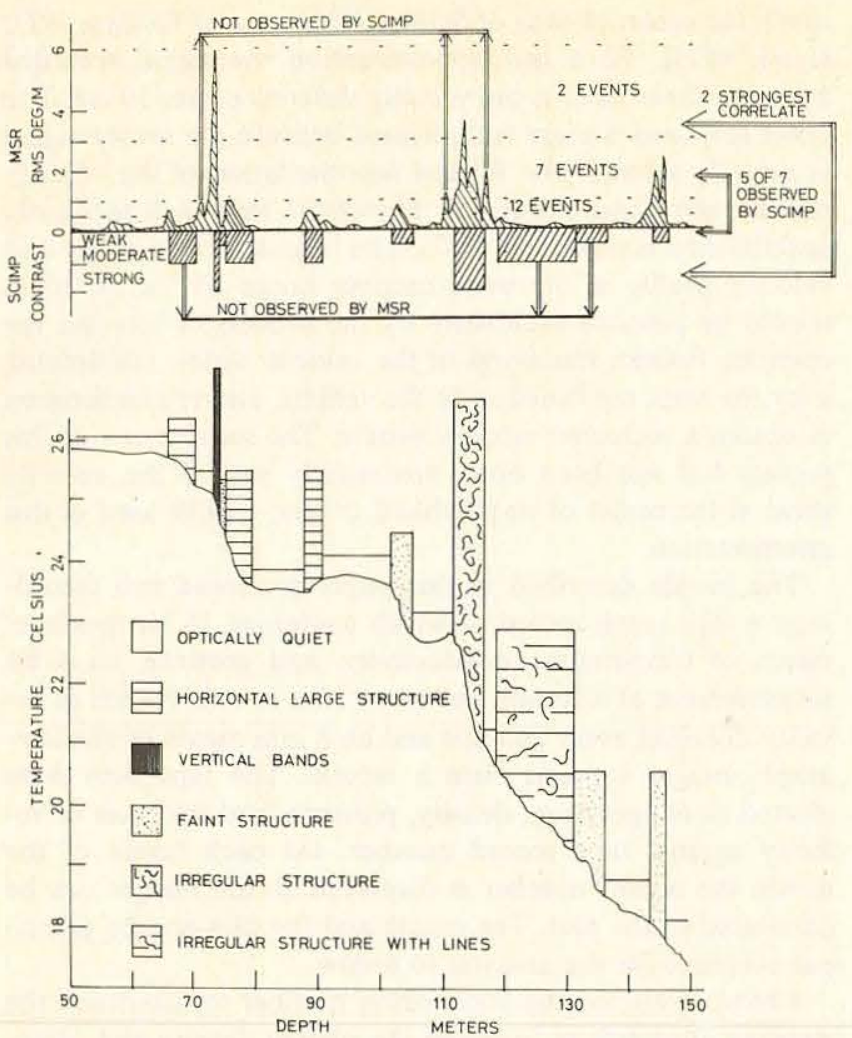

Fig. 1. Intercomparison of microstructure measurements by MSR and Scimp in the Gulf Stream. MSR measures temperature variance while Scimp measures optical structures. See the text for discussion of the comparison.

MSR. Two high mixing rate regions are shown, seven moderately high variance regions, and a total of 12 regions with variance of $\frac{1}{2} \mathrm{rms}$ degree/m or greater, well above the noise. The optical images of Scimp have been graded to a single measure of mixing in which many interfaces of high contrast rate as strong structure, fewer interfaces of lesser contrast as moderate structure, few interfaces of low contrast as weak structure, and no structure as blank. The correspondence is quite as good as one would expect. The two strongest features measured by each instrument correspond. Five of the seven moderately strong MSR events correspond to Scimp measurements. Two cases of microstructure observed by each instrument were not observed by the other. It is unlikely that one instrument would miss the feature observed by the other, so it is more likely that the feature was not distributed over the horizontal distance separating the two instruments. The key gives some idea of the type of microstructure observed by Scimp. The result of the intercomparison is that although MSR and Scimp measure somewhat different things, they each detect mixing.

Camel uses a small airfoil-of-revolution probe to measure velocity fluctuations at the dissipation scale. On dive 19 of Scimp, at $38^{\circ} 15^{\prime} \mathrm{n}, 69^{\circ} 07^{\prime} \mathrm{W}$, Camel passed close enough to Scimp to record a similar temperature profile although the thickness of layers and the extreme temperatures of layers observed on the two vehicles differed. This dive serves as an intercomparison of Camel measurements with Scimp measurements. The velocity structure agreed fairly well. The largescale velocity shears were found in the gradient regions, not the intrusion layers, in both cases. Small-scale velocity structure was recorded by $\mathrm{Camel}$ in the upper mixed layers above $25 \mathrm{~m}$, in the mixed fresh layer from 62 to $68 \mathrm{~m}$, and in the cold intrusion from 78 to $83 \mathrm{~m}$. These also showed finer scale velocity fluctuations on the Scimp acoustic current meter records. However, only one of these three regions showed pronounced optical microstructure, the $78-83 \mathrm{~m}$ layer. The low gradient regions are apparently turbulent, and eddy motion is responsible for the high variance in velocity. But since they are relatively well mixed, there is little structure optically. Camel measures the dissipation of large-scale shear in eddy motion while Scimp measures the mixing of heat and salt which only occurs where gradients in these quantities exist.

Dive 19 was the northernmost of a series of stations across the Gulf Stream. There was a progression in this series from Gulf Stream water toward slope water with an increase in layering as the front between the slope and stream was approached. The site of dive 19 was very near the surface expression of the front which was visible in the calm conditions that prevailed the 2 days of the stream section. The TS diagram in Figure 2 shows that the layers composing the water column at that location were mostly from two water types that did not quite represent slope water or stream water, but rather some mixture. The water types have been labeled 'mostly slope' and 'mostly stream' to reflect that they are not pure slope water or Gulf Stream water, but rather some intermediate masses. The layer at $66 \mathrm{~m}$ was distinctly fresher than the water mass labeled mostly slope. Deeper than $120 \mathrm{~m}$ the distinction between slope and stream is principally the isotherm depth rather than the TS characteristic, but the layering is not noticeable below $120 \mathrm{~m}$ where the water seems to be mostly of Gulf Stream origin.

Figure 3, the temperature profile, shows that slope type water is found from $0-10 \mathrm{~m}, 35-40 \mathrm{~m}, 50-70 \mathrm{~m}, 78-83 \mathrm{~m}$, and 105-115 m, while the rest is stream-type water. Expanded frames of the temperature and density profile will be used to discuss the microstructure observed optically on this descent. These are collectively Figure 4. Selected images from the dive are identified by record number both on the profile and on the image. The images are grouped together in Figure 5.

The first interval optically monitored is the isothermal layer from 20.3 to $25.8 \mathrm{~m}$ displayed in Figure $4 a$. This layer shows no optical structure and little velocity structure. At the base of the isothermal layer the density increases with a step discontinuity by $0.02 \sigma_{T}$ units. The velocity changes by about $1 \mathrm{~cm} / \mathrm{s}$ within the $50-\mathrm{cm}$ interval bracketing the interface giving a Richardson number of 1 . This is not low enough to produce shear instability at the moment of observation (though this interface may mix at other times). There are no stabilizing forces in the mixed layer so the small velocity that is observed there is characteristic of turbulent eddies rather than internal wave shear. Just above the density interface bounding the turbulent layer, optical images of vertical bands or plumes were recorded. (Note these could not have been artifacts of the instrument which had been in optically homogeneous water for almost $3 \mathrm{~m}$ and had not yet touched the warmer water.) This is evidently buoyant fluid rising from the interface at $25.8 \mathrm{~m}$. The vertical bands continue through the temperature gradient region though the density is not constant at the value of the warm core. A sequence of images is shown about record 2250 at $25.9 \mathrm{~m}$.

The vertical microstructure in the thick interface from 25.8 to $27.3 \mathrm{~m}$ is not the expected structure for such a region. The 


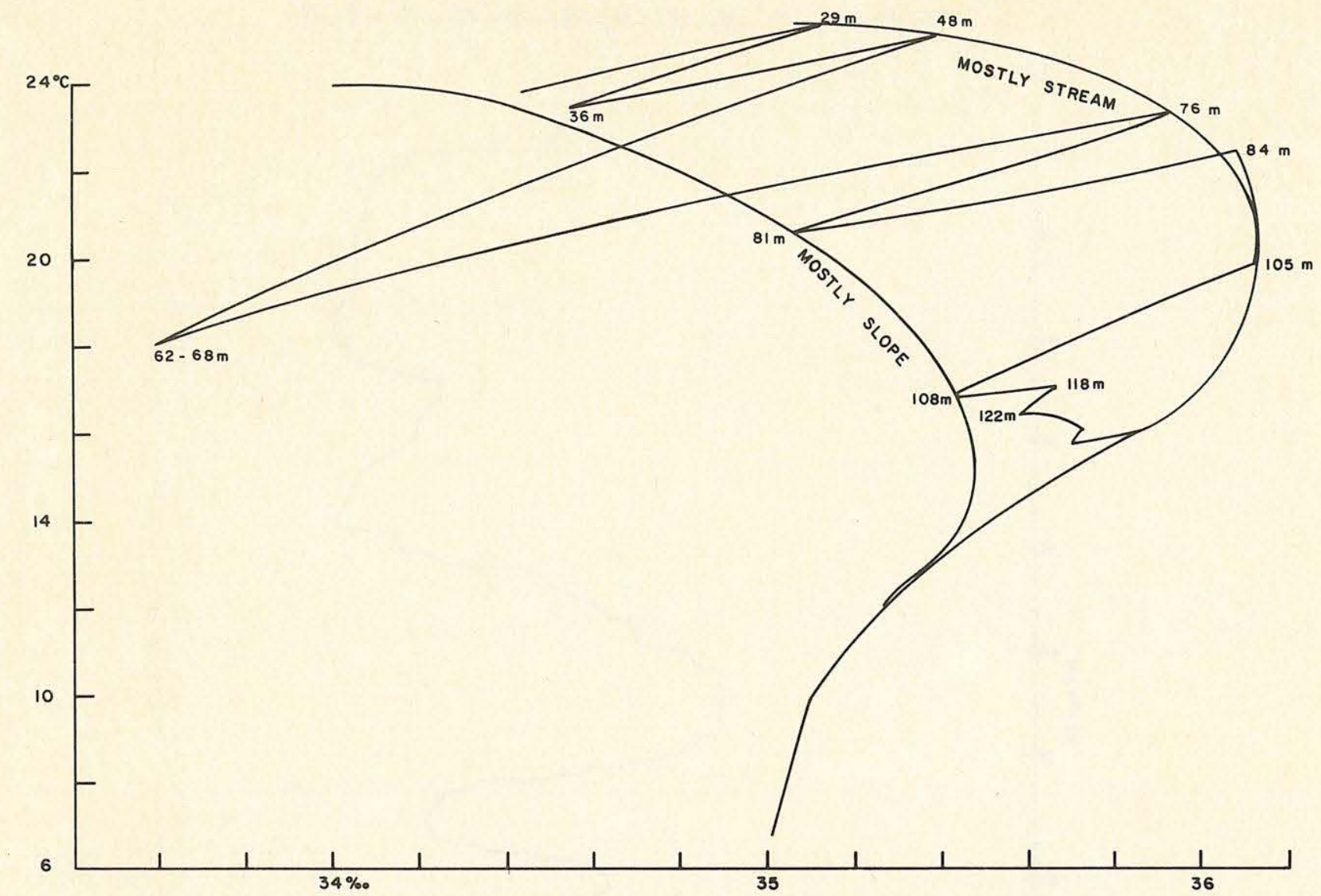

Fig. 2. TS diagram of Gulf Stream Front profile. Intrusions of water from a mass that is mostly slope water interleave with water from another mass that is mostly Gulf Stream water. The intrusion from 62 to $68 \mathrm{~m}$ is fresher than the other intrusions and may be undiluted slope water.

shear in this region is still $1 \mathrm{~cm} / \mathrm{s} / 50 \mathrm{~cm}$ which is sufficient to stir the constant density region. That it has not done so is evident in the temperature structure. Yet an ideal situation exists for triple diffusion. The temperature gradient is exactly balanced by the salinity gradient in density, and small turbulent eddies can mix the fluid locally (no overturning throughout the $1.5-\mathrm{m}$ interval is observed). Buoyancy would be produced when the heat diffused from the warm salty filaments in an eddy to the fresher cooler fluid. In support of this hypothesis, a 20 $\mathrm{cm}$ inversion in temperature can be seen at $26.2 \mathrm{~m}$. This could well be the effect of an eddy somewhat greater than $20 \mathrm{~cm}$ in diameter which has overturned the water column locally and carried shallower water to that depth. As the fresh cold water is warmed by its surroundings, it becomes buoyant and rises and later becomes visible as a buoyant plume elsewhere in the region. The whole region in which fluctuations in the density plot occur (an artifact of fluctuations in temperature and salinity at too small a scale for the CTD to represent accurately) displays vertical microstructure. The fluctuating density curve is a clue that there are small-scale gradients in temperature and salinity, and the occurrence of vertical microstructure is the consequence of double diffusion resulting from the smallscale stirring. The buoyant fluid penetrates into the mixed layer above the density interface implying that the density of the plumes is less than that of the source water by more than $0.02 \sigma_{T}$

The temperature maximum from 27.3 to $30.0 \mathrm{~m}$ is approximately isothermal and shows no optical structure, even at the edges. The shear is less than $10^{-2} / \mathrm{s}$ over $50 \mathrm{~cm}$ in this region, apparently so low that entrainment of different temperature fluid from the edges is not observed.

The density rises again at the bottom of the temperature maximum layer, but no optical microstructure occurs there. The next structures are seen at the very edge of the gradient region at $31.8 \mathrm{~m}$. In fact, through the entire gradient from 31.8 to $34.0 \mathrm{~m}$, vertical structure is observed. This gradient has the sense of a salt finger gradient, warm salty water over cool fresh water, but does not fit the scale or shape of a salt finger interface (except perhaps for the bottom at $33.8 \mathrm{~m}$ ). Again triple diffusion, partial stirring followed by double diffusion, seems to be the correct model for explaining the microstructure of this interface. The shear in the gradient region is 1 $\mathrm{cm} / \mathrm{s} / 50 \mathrm{~cm}$, while the density gradient is $0.02 \sigma_{T}$ in $50 \mathrm{~cm}$ giving a Richardson number of 1 , too large to overturn the entire gradient region, but small enough for local fluctuations or even salt finger convection to produce transient stirring. Two images from the gradient region are shown, the more uniform vertical bands at 2509 (32.7 m), reminiscent of salt fingers, and the chaotic bands at $2529(33.2 \mathrm{~m})$, looking more like stirring with buoyancy production. The sinking plumes penetrate the temperature minimum layer for $30 \mathrm{~cm}$, but no other structure is seen in the layer. It should be emphasized that plume formation is an intermittant process and should not be expected to be observed as much as $50 \%$ of the time.

As shown in Figure $4 b$, the transition between the minimum temperature water at $36.4 \mathrm{~m}$ and the temperature maxi- 

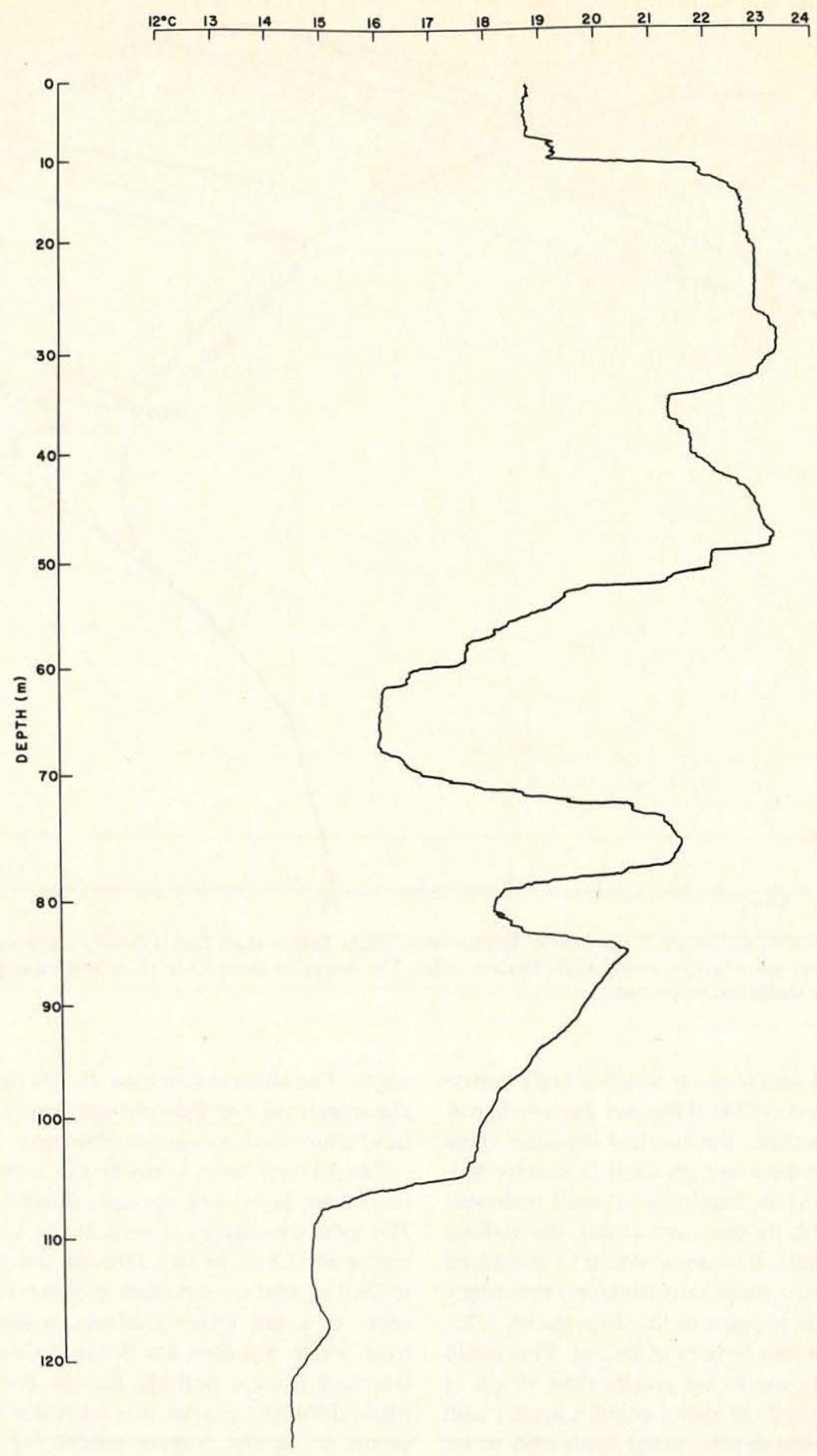

Fig. 3. Profile of temperature through Gulf Stream Front at $38^{\circ} 15^{\prime} \mathrm{N}, 69^{\circ} 07^{\prime} \mathrm{W}$. Scimp dive 19.

mum at $47.5 \mathrm{~m}$ is a rough staircase of the diffusive-interface type. Nine fairly sharp interfaces occur, but only three exhibit optical microstructure. These are at 41.9 (2848), 42.9 , and 44.7 $\mathrm{m}$. The structure at these interfaces is vertical bands or plumes, and in the case of the $42.9 \mathrm{~m}$ interface the plumes are irregular. These interfaces appear to be generating buoyancy, and since the mean shear across that part of the gradient is not large while the density step at each interface is $0.01 \sigma_{T}$, the interfaces are stable. Thus mechanical mixing is not a probable mechanism which leaves double diffusion as the mixing process at work.
The pronounced staircase from 36.4 to $39.8 \mathrm{~m}$ has little evidence of any mixing; for example, the image from 2765 (39.8 $\mathrm{m}$ ), where the gradient is sharp and the density step is 0.015 $\sigma_{T}$, shows no optical microstructure. The highest shear for the entire staircase is $1 \mathrm{~cm} / \mathrm{s} / 50 \mathrm{~cm}$, occurring in the middle of the isothermal layer at $38.0 \mathrm{~m}$. This is insufficient to overturn any interface though there could be turbulent eddies in the layers. The first layer at $37.0 \mathrm{~m}$ shows inversions in temperature that would appear to be stirring across the interface, but the images fail to confirm that any mixing is in progress.

Figure $4 c$ shows the transition from the $23.3^{\circ}$ water at 47.5 


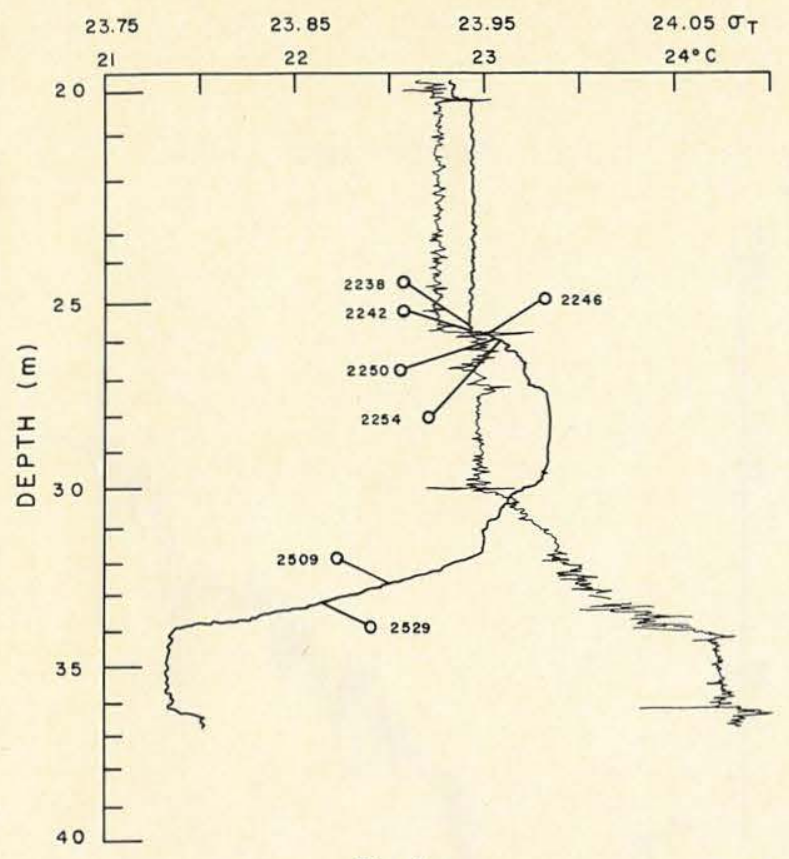

Fig. $4 a$

Fig. 4. Blown up sections of the temperature profile from $38^{\circ} 15^{\prime} \mathrm{N}, 69^{\circ} 07^{\prime} \mathrm{W}$. Density, the finer line, is plotted from calculations using conductivity, temperature, and pressure. The location of selected images is noted by record number.

$\mathrm{m}$ to the $16.1^{\circ}$ water at $61.8 \mathrm{~m}$. The first interface from 48.3 to $48.8 \mathrm{~m}$ has vertical microstructure which extends several tens of centimeters into the low gradient warm layer at the top (e.g., the image at 3097). The upper part of the interface is not a salt fingering region, although the gradients are correct for that. It rather appears to be mechanically stirred because the density gradient is not large at the upper interface while the shear exceeds $1.5 \mathrm{~cm} / \mathrm{s} / 50 \mathrm{~cm}$. The image at 3109 shows a chaotic but vertical structure. The lower interface is more like a salt finger interface in structure. It has a density step of 0.1
$\sigma_{T}$ so, although the shear is $2 \mathrm{~cm} / \mathrm{s} / 50 \mathrm{~cm}$, it is stable to shear instability. The highest gradient region is only 10 or $20 \mathrm{~cm}$ thick which is more like a salt finger interface encountered in quiet regions. The image at 3121 displays the vertical bands expected of fingers. No image was photographed in the center of the interface, so no positive identification is possible in this case.

The isothermal region from 48.8 to $50.3 \mathrm{~m}$ is apparently a thin intrusion intermediate in temperature and salinity to the rest of the region. There are only two images in the interior of this region that show optical microstructure. One is located at $3161(49.8 \mathrm{~m})$, the very middle of the region. The structure in these images is vertical. It appears that buoyant or heavy fluid from the high gradient regions bordering the isothermal region penetrates as deeply as $1 \mathrm{~m}$ into the isothermal region as plumes.

The image at $3197(50.3 \mathrm{~m})$ on the steep gradient region is chaotic but still retains a vertical alignment. This may actually be the superposition of turbulent eddies in one part of the optical path and buoyant plumes in another. The Richardson number is $\frac{1}{4}$ across this interface which confirms that mechanical stirring is probable. In any case, this region, like the one near $48.5 \mathrm{~m}$, is generating buoyancy by an incomplete mixing process followed by double diffusion.

There is an optically blank region from 50.8 to $51.1 \mathrm{~m}$ in the low gradient section between the mixing regions at 50.3 and $51.7 \mathrm{~m}$. Chaotic but vertical structure has encroached on either side of the blank $30-\mathrm{cm}$ interval from the mixing regions. The structure of 3232 at $51.3 \mathrm{~m}$ is quite similar to that of 3197 , except that the plumes are aligned $30^{\circ}$ clockwise from vertical. The process is probably the same, high shear and moderate density gradient yielding low Richardson number, and the rotation of the plumes from vertical reflects a local shear in velocity comparable to the growth rate of the plumes. The velocity change is $2 \mathrm{~cm} / \mathrm{s}$ over $50 \mathrm{~cm}$, and the window diameter is $2 \mathrm{~cm}$, giving a velocity difference between the edges of the field of view of $0.08 \mathrm{~cm} / \mathrm{s}$. Assuming the bands are streak lines of rising fluid, the rising speed would be $0.14 \mathrm{~cm} / \mathrm{s}$ to incline

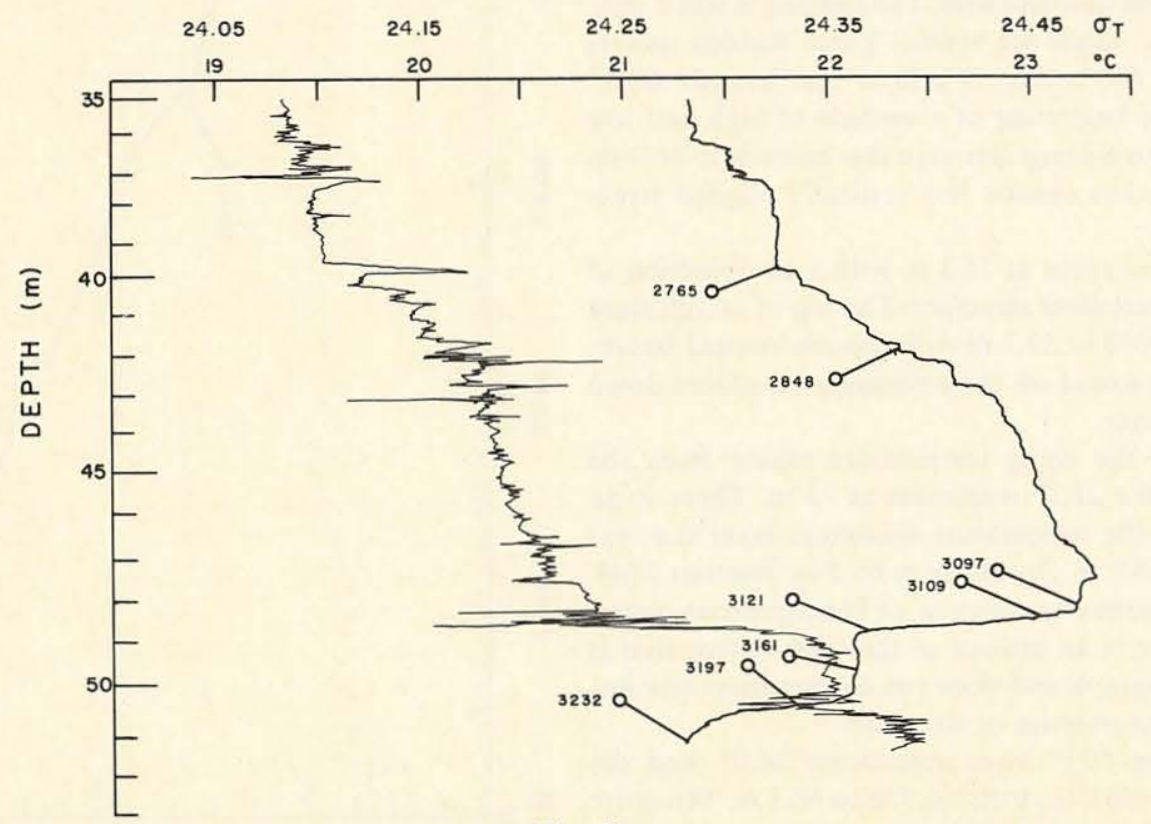

Fig. $4 b$ 
the streaks $30^{\circ}$ to the vertical. It is assumed the streak is recent, because as time passes this initial inclination will increase. The optical contrast will decrease, however, making the streaks less visible.

The highest gradient in the transition from $23.3^{\circ}$ to $16.1^{\circ}$ water is the $1^{\circ}$ step in about $10 \mathrm{~cm}$ at $51.7 \mathrm{~m}$. The sharpness of the density step makes the $\frac{1}{2} \mathrm{~cm} / \mathrm{s} / 50 \mathrm{~cm}$ shear at that point insufficient to mix the interface mechanically. Yet the image at 3252 , in the center of the interface, is more chaotic than the one at 3232 , although there are several vertical filaments in the image. This interface resembles the ideal salt finger interface more than any other in the layered structure of this profile. Yet the structure of the image is less like the ideal salt finger structure than almost any other selected. Examining the image more closely, one can see there are actually two sets of parallel, though wavy, lines: one set vertical, with spacing of $2.2 \mathrm{~mm}$; the other $60^{\circ}$ clockwise, with a spacing of $3 \mathrm{~mm}$. The two sets modulate one another so that each looks dashed in places. Finally, an extra line at the lower right confuses the picture and makes it difficult to decode.

The $2.2 \mathrm{~mm}$ vertical bands fit the pattern for salt fingers in very high gradients; in fact, they closely resemble fingers generated in the laboratory with similar gradients [Williams, $1974 b$ ]. The rotated bands in the same image present a greater problem in interpretation. Since they appear to be regularsix or seven appear - they are not likely to be a random interface convoluted by stirring. If one assumes they are also salt fingers, they must be rotated by some means, either by alignment to shear while growing or by reorientation during some overturning process. Shear causes salt finger alignment in plates or lamellae parallel to the shear [Linden, 1974]. Thus one would not expect to see them unless looking edge on, in which case they would be vertical. So sheared fingers are not a likely explanation. The other explanation fares little better. The density contrast at the interface inhibits shear instability although the interface may become distorted. However, it would be displaced vertically by this distortion, not rotated. Furthermore, two quite different orientations in regions only $80 \mathrm{~cm}$ apart, the optical path length, is hard to explain.

At $52.5 \mathrm{~m}$ the image marked 3284 shows salt finger-like bands rotated $60^{\circ}$ counterclockwise. The spacing is still $2 \mathrm{~mm}$, although only a few bands are visible. These banded images occur in a group at the bottom of a layer that bounds the $1^{\circ}$ step. This marks the beginning of a cascade of high and low gradients, rather than a sharp staircase that extends to $56.3 \mathrm{~m}$. Most of this region has chaotic but vertically aligned structure.

The staircase starts again at $56.3 \mathrm{~m}$ with a combination of vertical bands and turbulent structure. The top of an interface is shown as image 3538 at $59.7 \mathrm{~m}$ with chaotic vertical bands. Vertical structure is found on the remaining interfaces down to the cold mixed layer.

Figure $4 d$ covers the rising temperature region from the $16.1^{\circ}$ minimum to the $21.5^{\circ}$ maximum at $75 \mathrm{~m}$. There is no optical structure in the temperature minimum layer that extends from 62.0 to $66.9 \mathrm{~m}$. An image at $65.3 \mathrm{~m}$, number 3749 , represents the featureless appearance of homogeneous water. The granular texture is an artifact of the laser source that is used for the shadowgraph and does not change from one image to the next in the absence of structure.

The bottom of the $16.1^{\circ}$ layer approaches $16.0^{\circ}$, and the density increases by $0.025 \sigma_{T}$ from $66.9 \mathrm{~m}$ to $68.1 \mathrm{~m}$. Structure reappears in the lowest part of this layer, and the image 3856

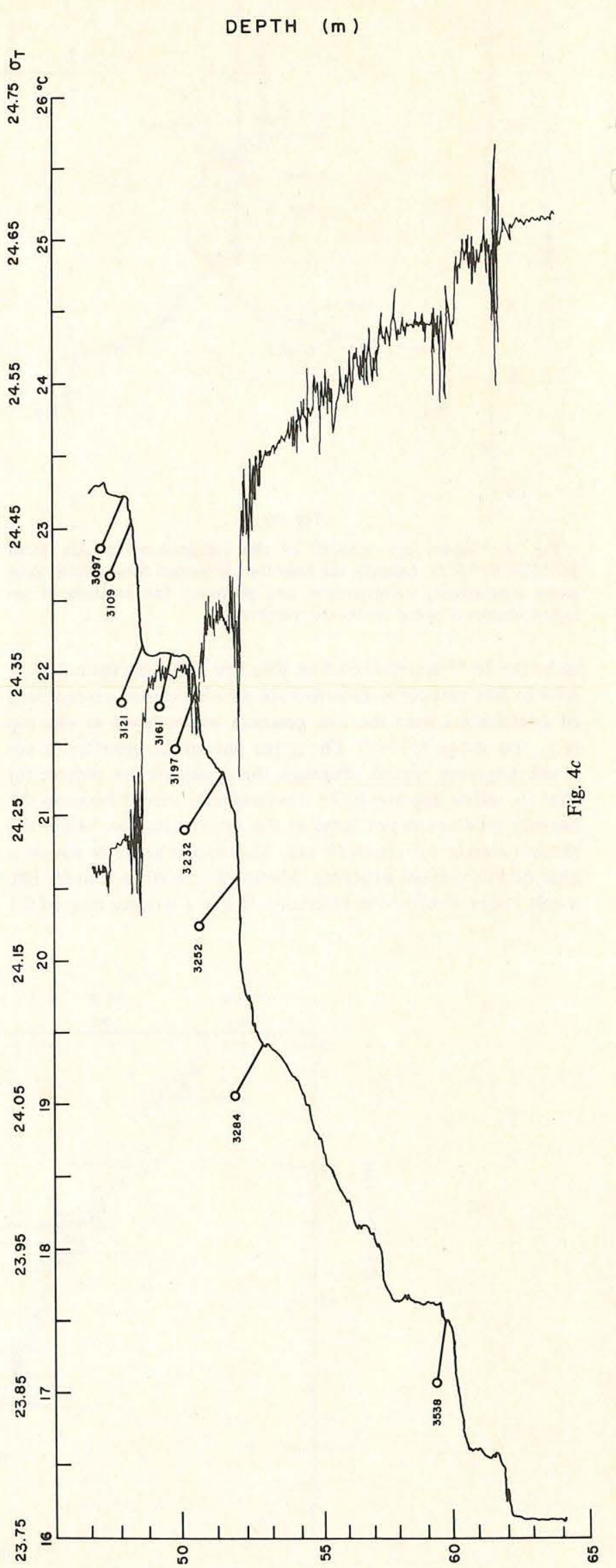


Williams: Double Diffusion in Gulf Stream

1925

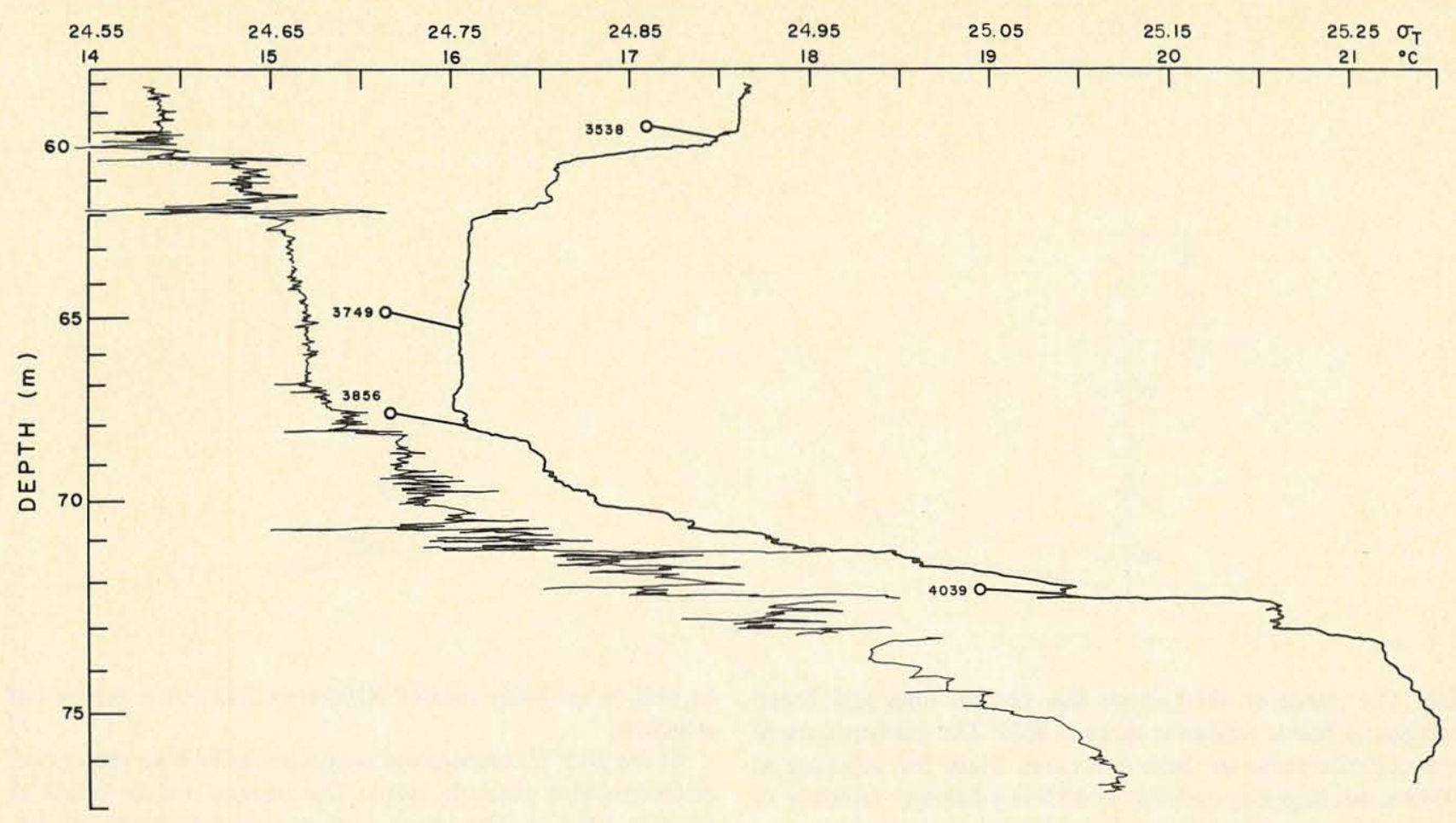

Fig. $4 d$

at the top of the first interface shows the vertical plumes produce in this diffusive interface. Similar images occur on the interface at $70.0 \mathrm{~m}$ and in the region from there to $71.5 \mathrm{~m}$. The velocity structure is not pronounced in this region, the maximum being about $\frac{1}{2} \mathrm{~cm} / \mathrm{s} / 50 \mathrm{~cm}$. But the large gradients in temperature and salinity are indicated by the spiking of the density plot.

The last steps in the rising temperature region are especially large. The temperature rises $3^{\circ}$ from 71.5 to $73.5 \mathrm{~m}$ in about three steps. The structure is particularly strong in this region, the image 4039 from $72.2 \mathrm{~m}$ showing this. The pattern is chaotic, but there are two horizontal bands and several fine vertical lines. The former may be turbulent eddies driven by buoyancy flux which are carrying inhomogeneous fluid. The vertical lines are probably thermal plumes from the interface below.

Figure $4 e$ is the cold layer at $80 \mathrm{~m}$ with the gradient regions on either side. From 74.8 to $76.4 \mathrm{~m}$, there is no optical structore. The gradient region from 76.4 to $79.5 \mathrm{~m}$ displays vertical and chaotic structure with only a few interruptions. The salt finger type interfaces from 77.0 to $78.6 \mathrm{~m}$ have a Richardson number of 1.5 , implying the convection observed is salt finger-

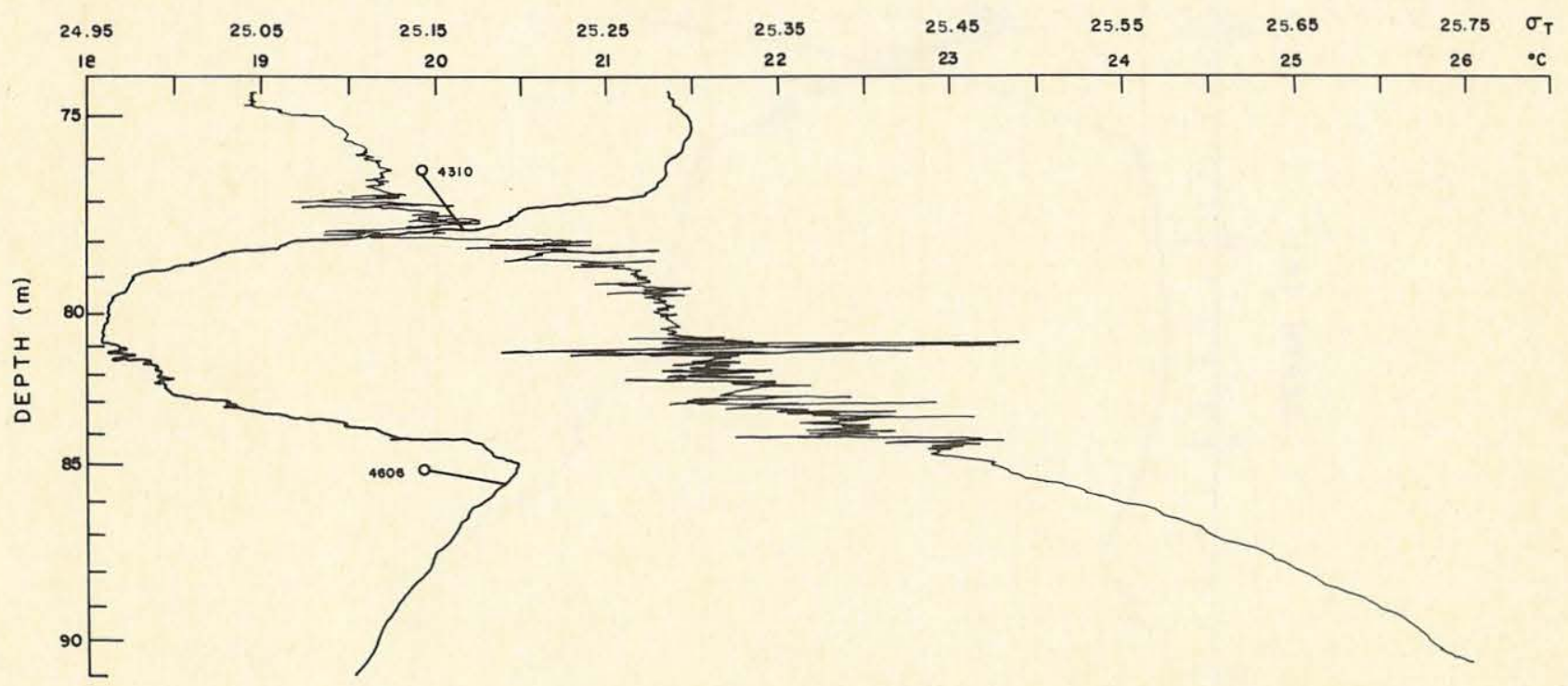

Fig. $4 e$ 


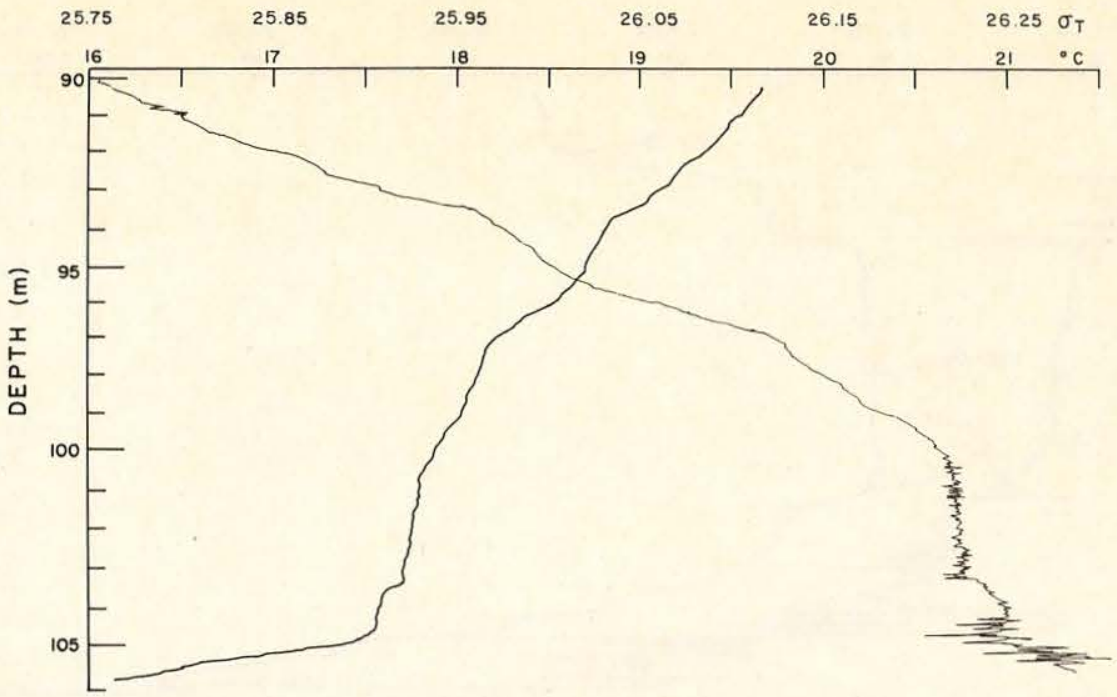

Fig. $4 f$

ing. The image at 4310 shows fine vertical lines and broad horizontal bands similar to those at 4039 . The gradients are of the opposite sense in these two cases. Since the structure at 4310 is salt fingering and that at 4039 is a diffusive interface or triple diffusion, the buoyancy generating process must produce similar images.

From 78.6 to $79.5 \mathrm{~m}$ the vertical structure continues. The mixing region above drives these negatively buoyant plumes into the cold layer. From 79.5 to $80.5 \mathrm{~m}$ there is no structure; it then starts again at the bottom of the cold layer from 80.6 to $81.0 \mathrm{~m}$ with vertical bands from the diffusive interface region below the cold layer. The image at $4430(80.6 \mathrm{~m})$ shows a banded pattern crossed on the right with a plume.

The Richardson number is 0.32 from 81.0 to $84.9 \mathrm{~m}$ which puts the whole region on the verge of overturning. The shear is a steady $1.5 \mathrm{~cm} / \mathrm{s} / 50 \mathrm{~cm}$ for this $4-\mathrm{m}$ interval, while the density changes $0.15 \sigma_{T}$. The optical structure contains chaotic as well as vertically banded structures. The entire region has structure.

At the $20.5^{\circ} \mathrm{C}$ temperature maximum at $84.9 \mathrm{~m}$, the optical microstructure abruptly stops. The images remain blank or weak to $103.4 \mathrm{~m}$. The image at 4606 at $85.3 \mathrm{~m}$ shows this homogeneity.

The warm region shown in Figure $4 f$ has sufficient stability so that the shear which occurs there is unable to cause mixing. The region is uniform in density gradient and is devoid of optical structure. From 100.5 to $103.4 \mathrm{~m}$ the density gradient is low, but the shear is low also. There may be overturning or convection in the layer, but no pronounced optical microstructure is visible.

At $103.4 \mathrm{~m}$ and continuing into Figure $4 \mathrm{~g}$ to $107.4 \mathrm{~m}$, a high gradient region shows optical microstructure, both vertical and chaotic. The density profile changes from smooth to spiky at $103.4 \mathrm{~m}$, reflecting the small scale gradients in temperature

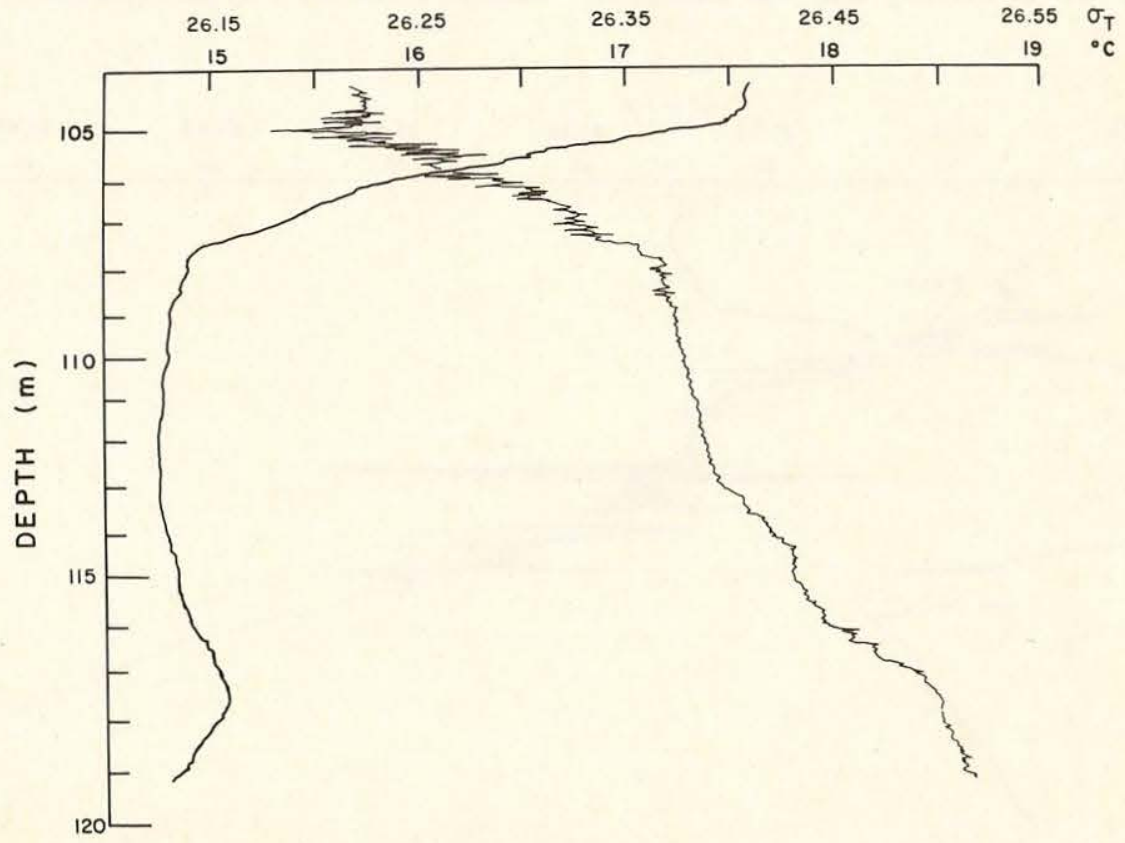

Fig. $4 g$ 

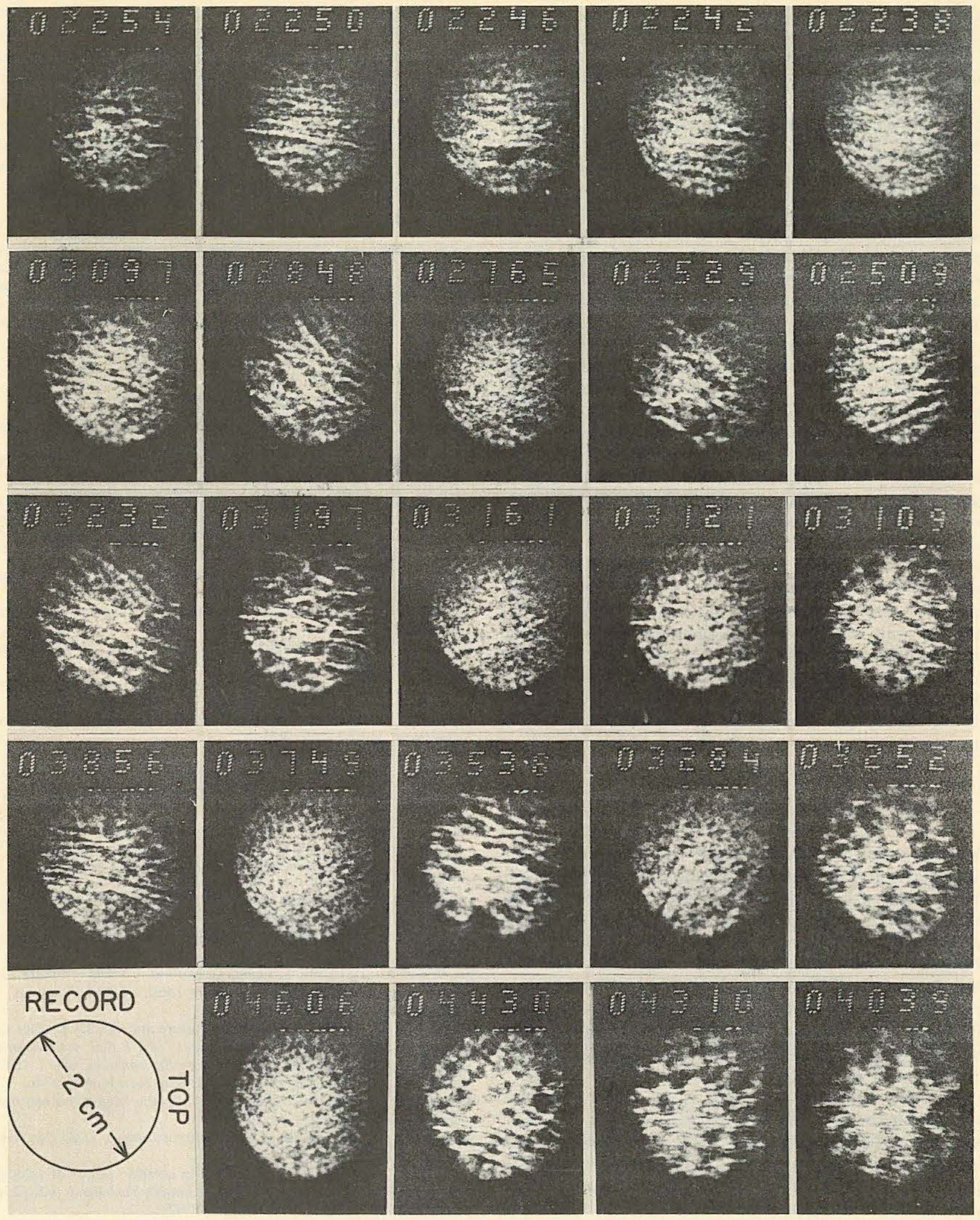

Fig. 5. Microstructure images from Scimp dive 19. The record number on each film frame identifies the position on the profile at which it was taken. The image is the horizontal shadowgraph taken through $80 \mathrm{~cm}$ of water. The diameter of the image is $2 \mathrm{~cm}$. 
and salinity that the sensors cannot track perfectly. This continues to the cold layer at $107.4 \mathrm{~m}$.

Although the intrusions and layering continue with a cold layer from 107.4 to $112.0 \mathrm{~m}$, a warming gradient from 112.9 to $117.5 \mathrm{~m}$, and a cooling gradient from $117.5 \mathrm{~m}$ to the end of the dive, there is no more noticeable optical microstructure on the dive.

In summary, the interfaces between the warm and cold layers of this set of frontal intrusions display diffusive microstructure either plain salt fingers or diffusive interfaces but also they display triple diffusion microstructure and buoyant plumes from the interfaces where double diffusion is operative. In some regions the mixing is purely mechanical, and the structures are chaotic without any gravitational orientation.

Purely diffusive interfaces occur from 41.6 to $43.2 \mathrm{~m}$. The remainder of the regions with cool fresh water overlying warm salt water have low Richardson numbers and display a mixture of chaotic and vertical structure. I conclude that triple diffusion is the dominant process of mixing in these regions.

Unsheared salt finger interfaces occur in three places: 48.5$48.8 \mathrm{~m}, 51.4-52.5 \mathrm{~m}$, and $77.0-78.6 \mathrm{~m}$. The rest of the gradient regions where warm salty water overlies cool fresh water seem to be mechanically stirred because they have a low Richardson number and display mixed chaotic and vertical structures. Thus while triple diffusion is not quite as dominant in these regions, it is the most common mixing process. Few high contrast images display chaotic structure without vertical orientation. The only region showing a significant number of these images is the cold layer between 77.0 and $84.1 \mathrm{~m}$. This is the region with the highest sustained velocity shear and also appears to have the greatest mechanical stirring. But even in this region, most images show vertical structure as well as chaotic structure.

\section{CONCLUSIONS}

Near the Gulf Stream Front, a complicated layered structure exists in which intrusions of water from both sides of the front are found. The interfaces between these layers are of the right temperature and salinity gradients to permit double diffusive mixing, either by the salt fingering process or by the diffusive interface process. However, velocity shear from internal waves and advection mechanically stir these interfaces. The Richardson number is generally below 1 and often below $\frac{1}{2}$ so that Kelvin-Helmholtz instabilities are likely to occur when a transient shear is added to the mean shear. Certain layers with little or no density gradient are turbulent. Eddy motions may entrain fluid at the edges of the layer and mix it through the interior.

Images of the mixing structures in this region show that complete mechanical mixing is generally not the process of importance. The structures are vertically aligned in most cases. The implication of vertically aligned structures is that fluids are convecting owing to buoyancy which only can be generated in a mixing process if there is double diffusion. Since the shear is sometimes sufficient to permit overturning and since the structures are chaotic, a process that generates buoyancy yet is mechanically stirred has been invoked. This process depends on the temperature and salinity contrasts between the stirred fluids to match approximately the densities, and it depends on the stirring to be intermittent. Then when the stirred region has reached a degree of fineness that diffusion of velocity (viscous dissipation) erases shear, double diffusion of heat and salt can proceed to generate warm fresh and cool salty fluids on the two sides of each interface. The buoyant and dense fluids then convect from the stirred region into the unstirred regions abutting the overturned volume. This process, a kind of triple diffusion, is the most common one in the Gulf Stream Front region studied in this profile.

Acknowledgment. I acknowledge M. Gregg for his MSR data, A. Gargett for her Camel data, P. Hendricks for his assistance in data processing, and T. Sanford, chief scientist on KNORR Cruise 52, for his generous help. This work was supported on ONR contract N00014-74-C-0262, NR 083-004. The W.H.O.I. contribution number is 4243 .

\section{REFERENCES}

Eckart, C., An analysis of the stirring and mixing processes in incompressible fluids, J. Mar. Res., 7, 265-275, 1948.

Gregg, M. C., Microstructure and intrusions in the California current, J. Phys. Oceanogr., 5, 253-278, 1975.

Gytre, T., Ultrasonic measurements of ocean currents down to $1 \mathrm{~mm} /$ sec, paper presented at the Conference Proceedings 32, I.E.R.E., Conference on Instrumentation in Oceanography, University College, N. Wales, Bangor, U.K., September 23-25, 1975.

Horne, E. P. W., Interleaving at the subsurface front in the slope water off Nova Scotia, J. Geophys. Res., 83, 3659-3671, 1978.

Linden, P. F., Salt fingers in a steady shear flow, Geophys. Fluid Dyn., 6, 1-27, 1974.

Molcard, R. and A. J. Williams, III, Deep stepped structure in the Tyrrhenian Sea, Mem. Soc. R. Sci. Liege, 6, 191-210, 1975.

Munk, W., and C. Garrett, Internal wave breaking and microstructure, Boundary Layer Meteorol., 4, 37-45, 1973.

Osborn, T. R., Vertical profiling of velocity microstructure, J. Phys. Oceanogr., 4, 109-115, 1974.

Osborn, T. R., Measurements of energy dissipation adjacent to an island, J. Geophys. Res., 83, 2939-2958, 1978.

Stern, M. E., and J. S. Turner, Salt fingers and convecting layers, Deep Sea Res., 16, 497-511, 1969.

Tait, R. I., and M. R. Howe, Some observations of thermo-haline stratification in the deep ocean, Deep Sea Res., 15, 275-280, 1968.

Turner, J. S., Salt fingers across a density interface, Deep Sea Res., 14, 599-611, 1967.

Turner, J. S., The behaviour of a stable salinity gradient heated from below, J. Fluid Mech., 33, 183-200, 1968.

Turner, J. S., Double-diffusive intrusions into a density gradient, $J$. Geophys. Res., 83, 2887-2901, 1978.

Voorhis, A. D., D. C. Webb, and R. C. Millard, Current structure and mixing in the shelf/slope water front south of New England, $J$. Geophys. Res., 81, 3695-3708, 1976.

Williams, A. J., III, Free-sinking temperature and salinity profiler for ocean microstructure studies, in Oceans '74 I.E.E.E. International Conference on Engineering in the Ocean Environment, vol. 2, Institute of Electrical and Electronic Engineers, New York, 1974a.

Williams, A. J., III, Salt fingers observed in the Mediterranean outflow, Science, 185, 941-943, $1974 b$.

Williams, A. J., III, Images of ocean microstructure, Deep Sea Res., 22, 811-829, 1975.

Williams, A. J., III, and J. S. Tochko, An acoustic sensor of velocity for benthic boundary layer studies, in Bottom Turbulence, edited by J. C. J. Nihoul, Elsevier, New York, 1977.

Woods, J. D., and R. L. Wiley, Billow turbulence and ocean microstructure, Deep Sea Res., 19, 87-121, 1972.

(Received October 31, 1978; revised July 29,1980 ; accepted September 4, 1980.) 


\section{MANDATORY DISTRIBUTION LIST}

FOR UNCLASSIFIED TECHNICAL REPORTS, REPRINTS, AND FINAL REPORTS PUBLISHED BY OCEANOGRAPHIC CONTRACTORS

OF THE OCEAN SCIENCE AND TECHNOLOGY DIVISION

OF THE OFFICE OF NAVAL RESEARCH

(REVISED NOVEMBER 1978)

1 Deputy Under Secretary of Defense (Research and Advanced Technology) Military Assistant for Environmental Science Room 3D129

Washington, D.C. 20301

Office of Naval Research 800 North Quincy Street

Arlington, VA 22217

3 ATTN: Code 483

1 ATTN: Code 460

2 ATTN: 102B

1 CDR J. C. Harlett, (USN)

ONR Representative Woods Hole Oceanographic Inst. Woods Hole, MA 02543

Commanding Officer Naval Research Laboratory Washington, D.C. 20375

6 ATTN: Library, Code 2627
12 Defense Documentation Center Cameron Station Alexandria, VA 22314 ATTN: DCA

Commander Naval Oceanographic Office NSTL Station

Bay St. Louis, MS 39522

1 ATTN: Code 8100

1 ATTN: Code 6000

1 ATTN: Code 3300

1 NODC/NOAA

Code D781

Wiscons in Avenue, N.W. Washington, D.C. 20235 
UNCLASSIFIED $\quad 5 / 81$

SECURITY CLASSIFICATION OF THIS PAGE (When Data Entered)

\begin{tabular}{|c|c|c|}
\hline \multicolumn{2}{|r|}{ REPORT DOCUMENTATION PAGE } & $\begin{array}{l}\text { READ INSTRUCTIONS } \\
\text { BEFORE COMPLETING FORM }\end{array}$ \\
\hline & \begin{tabular}{l|l|} 
REPORT NUMBER & 2. GOVT ACCESSION NO. \\
WHOI $-81-42$ &
\end{tabular} & 3. RECIPIENT'S CATALOG NUMBER \\
\hline \multirow{2}{*}{\multicolumn{2}{|c|}{$\begin{array}{l}\text { TITLE (and Subtilte) } \\
\text { THE ROLE OF DOUBLE DIFFUSION IN A GULF STREAM } \\
\text { FRONTAL INSTRUSION }\end{array}$}} & $\begin{array}{l}\text { 5. TYPE OF REPORT A PERIOD COVERED } \\
\text { Technical }\end{array}$ \\
\hline & & $\begin{array}{l}\text { 6. PERFORMING ORG. REPORT NUMBER } \\
\text { WHOI CONt. } 4243\end{array}$ \\
\hline \multicolumn{2}{|r|}{$\begin{array}{l}\text { 7. AUTHOR(o) } \\
\text { Albert J. Williams, III }\end{array}$} & $\begin{array}{l}\text { 8. CONTRACT OR GRANT NUMBER(B) } \\
\text { N00014-74-C-0262; NR 083- } \\
004\end{array}$ \\
\hline \multicolumn{2}{|r|}{$\begin{array}{l}\text { PERFORMING ORGANIZATION NAME AND ADDRESS } \\
\text { Woods Hole Oceanographic Institution } \\
\text { Woods Hole, Massachusetts } 02543\end{array}$} & $\begin{array}{l}\text { 10. PROGRAM ELEMENT, PROJECT, TASK } \\
\text { AREA Q WORK UNIT' NUMBERS TAK } \\
\text { NR } 083-004\end{array}$ \\
\hline \multirow[t]{2}{*}{11.} & \multirow{2}{*}{$\begin{array}{l}\text { CONTROLLING OFFICE NAME AND ADDRESS } \\
\text { NORDA/National Space Technology Laboratory } \\
\text { Bay St. Louis, MS } 39529\end{array}$} & $\begin{array}{l}\text { 12. REPORT DATE } \\
\text { MaY } 1081\end{array}$ \\
\hline & & 13. NUMBER OF PAGES \\
\hline \multirow{2}{*}{\multicolumn{2}{|c|}{ 14. MONITORING AGENCY NAME \& ADDRESS(If different from Controlline OIflce) }} & $\begin{array}{l}\text { 15. SECURITY CLASS. (of thit ropore) } \\
\text { Unclassified }\end{array}$ \\
\hline & & $\begin{array}{l}\text { 15a. DECLASSIFICATION/DOWNGRADING } \\
\text { SCHEDULE }\end{array}$ \\
\hline \multicolumn{3}{|c|}{$\begin{array}{l}\text { 16. DISTRIBUTION STATEMENT (of thla Roport) } \\
\text { Approved for public release; distribution unlimited. }\end{array}$} \\
\hline
\end{tabular}

17. DISTRIBUTION STATEMENT (of the abetract ontered in Block 20, if difforent trom Roport)

18. SUPPLEMENTARY NOTES

Reprinted from: Journal of Geophysical Research 86(C3): 1917-1928 (March 20, 1981).

19. KEY WORDS (Continue on roveree aldo if noceseary and identify by block number)

1. Double diffusive mixing

2. Optical microstructure

3. Frontal mixing

20. ABSTRACT (Confinue on reverae ofdo if neceseary and ldentify by block number)

See reverse side. 
20.

Double diffusive convection is possible where large vertical gradients in temperature and salinity tend to compensate in density. Frontal intrusions have these large gradients and can provide the possibility for a salt finger interface at one boundary and a diffusive interface at the other. But large vertical gradients of velocity are present at the boundaries of intrusions, which cause mechanical stirring and turbulent mixing as well. In the exceptionally active intrusions at the Gulf Stream Front near $38^{\circ} \mathrm{N} 69^{\circ} \mathrm{W}$, a convective process resulting from incomplete mechanical mixing was observed photographically on both intrusive boundaries. 


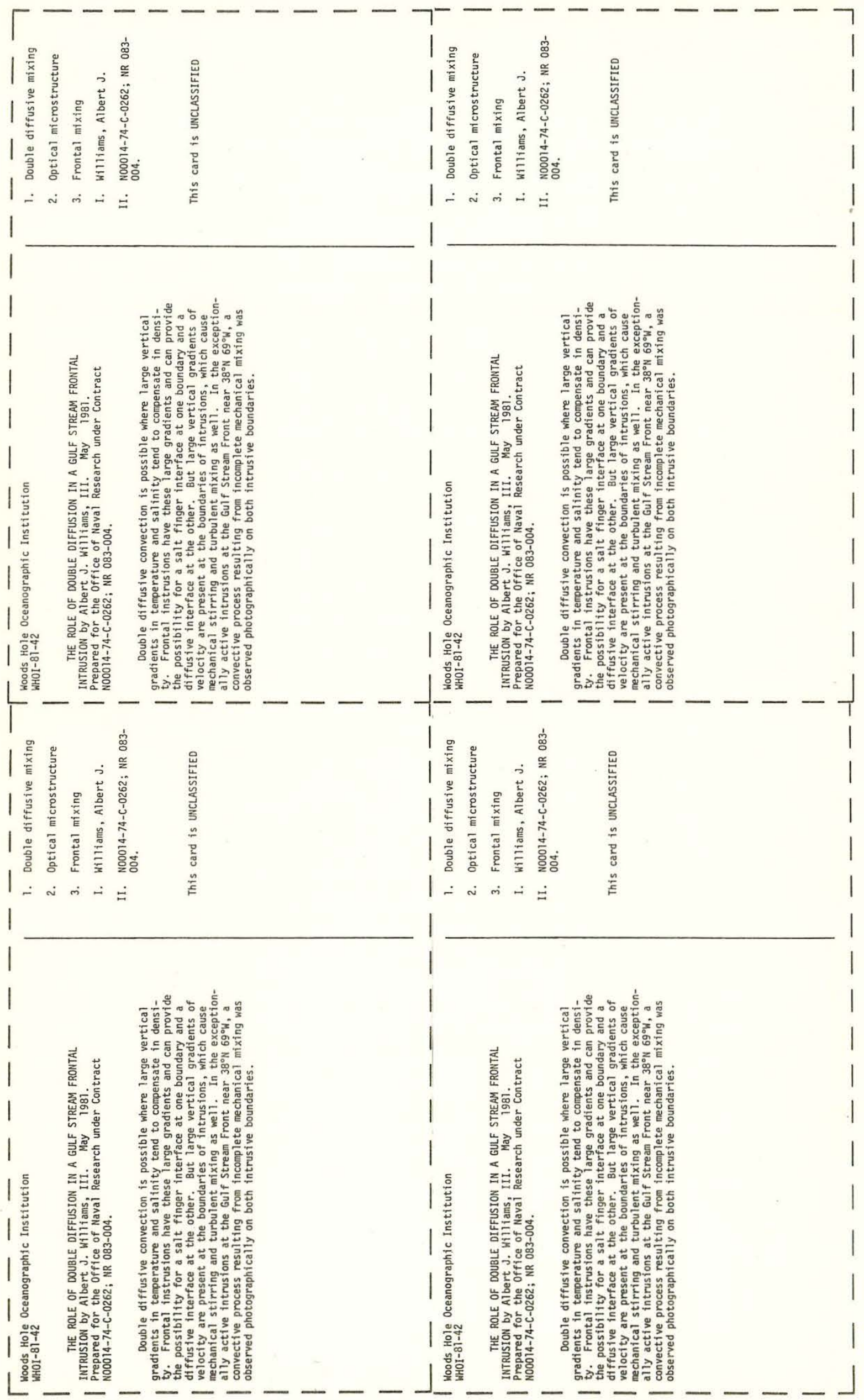

